\title{
A presença do improviso na prática da docência
}

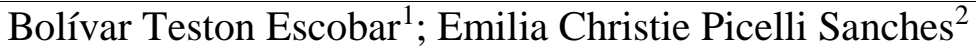

\section{Resumo}

Este artigo se propõe a discutir sobre a prática do improviso e suas manifestações na docência, em especial na área do ensino superior em design. Primeiramente é apresentado o conceito de ensino tradicional e seu posicionamento perante a prática do improviso. Em sequência, visões contemporâneas inclusivas ao improviso são descritas em contraponto, para então serem apresentados alguns depoimentos de professores de cursos superiores de design sobre a prática. Por fim, nas considerações finais, são apresentados desdobramentos possíveis a essa discussão.

Palavras Chave: Improviso; Ensino, Design.

\section{Introdução}

Improviso. Adjetivo que significa "que se improvisou; que se realiza de maneira repentina e inesperada; imprevisto, repentino", ou também substantivo masculino que se define por "algo que é dito ou feito sem nenhuma preparação ou ensaio prévio.” (MICHAELIS, 2016).

Geralmente associado com o campo das artes cênicas, conforme observa Cunha et. al. (2015), o improviso aparece como uma contraparte do que é organizado: algo que é espontâneo, súbito, que surge fora do planejamento ou da organização. Quando visto sob a perspectiva de outras áreas, como a educação, o improviso apresenta potencial para ser discutido como ferramenta ou prática recorrente dentro da sala de aula, tanto por parte dos alunos quanto dos professores.

O presente artigo visa estabelecer algumas considerações sobre a presença do improviso na prática da docência. Entendemos que a profissão do ensino está inserida em paradigmas que partem tanto de ideias tradicionais de métodos e abordagens para a prática, quanto de contínuas propostas e inovações que surgem como promessa de melhoria para o campo. Isso

\footnotetext{
${ }^{1}$ Mestrando em Design pela Universidade Federal do Paraná - UFPR, na linha de Sistemas de Informação, com pesquisa na área da infografia sobre saúde voltada para o ensino à distância. bolivarescobar@gmail.com.

${ }^{2}$ Mestranda em Design pela Universidade Federal do Paraná - UFPR, na linha de Sistemas de Informação, com pesquisa na área de acessibilidade para cegos. emilia.ecps@gmail.com.
} 
posto, perguntamos: como o improviso aparece na relação ensino-aprendizagem por parte dos professores?

Inicialmente, propõe-se uma visão do didatismo tradicional e seu posicionamento perante a prática do improviso. Em seguida, apresentamos algumas novas visões contemporâneas sobre o ato de improvisar quando recorrente em organizações e instituições, bem como sua potencial aplicação em sala de aula. A argumentação recebe alguns depoimentos de professores de cursos superiores de design em relação à presença do improviso em suas carreiras.

Demonstra-se que o improviso, constatado sua inevitabilidade, é uma ferramenta potencialmente benéfica tanto para alunos, que podem exercitar a prática como uma forma de desaprendizagem (ALMEIDA, 2013), quanto para professores, que podem recorrer a ele como uma estratégia alternativa aos métodos tradicionais que se revelam não tão eficazes na condução de aulas ou situações específicas no contexto da aprendizagem.

\section{O ensino tradicional e sua relação com o improviso}

O ensino tradicional, ou o que Rodrigues et. al. (2011) chamam de "didática tradicional”, tem como fundamento o predomínio do ensino sobre a aprendizagem, ou seja, há o domínio do professor em repassar conteúdo dentro de sala de aula, de forma autoritária, na expectativa de que os alunos apenas retenham tal informação de forma mecânica - sem levar em consideração suas peculiaridades, características ou dificuldades. Os alunos, por sua vez, só possuem voz quando existe uma pergunta do professor direcionada a eles (RODRIGUES et. al., 2011).

Tal ensino, como aponta Almeida (2015, p. 158), foi uma escolha, já que “dentre as pedagogias possíveis e de acordo com determinada concepção de Educação, elegeu-se uma, a [que se considera] melhor ou mais adequada para determinados fins". Ainda segundo o autor, as ações pedagógicas resultantes dessa escolha seriam a "contenção das manifestações indesejáveis" e "desenvolvimento dos potenciais que se elege intensificar" (idem).

Pelo mesmo viés, Sawyer (2004) discorre sobre como o professor, no ensino tradicional, é tratado como um "ator mecânico". Os docentes atuam em sala de aula para sua audiência (os alunos), e todo tipo de fala - seja dos professores ou dos alunos - é roteirizado previamente (SAWYER, 2004, p. 12). Esse roteiro sem flexibilidade apresenta todo o 
conteúdo e ações que o professor deve seguir, eliminando qualquer tipo de criatividade da sala de aula, e diminuindo a capacidade do docente de agir diante de imprevistos.

Colli (1996) nos fornece algumas pistas sobre esse atual posicionamento da sociedade perante as ocorrências do improviso em contextos profissionais. O autor, na sua interpretação sobre o surgimento da filosofia até sua proclamação como gênero literário (COLLI, 1996, p. 92), reflete sobre a prática da dialética, conduzida pelos oradores gregos como uma atividade intelectual pública, na qual dois "debatedores" discutiam assuntos variados - discussões essas que se materializaram em forma dos diálogos que seriam transcritos como registros dos textos filosóficos da época.

O improviso perdeu importância na prática da dialética porque um texto escrito, elaborado e ensaiado com antecedência tinha mais chances de prender a atenção do público e de desenvolver o argumento com mais eficácia (COLLI, 1996, p. 88). Os diálogos tornaramse praticamente declamações, leituras em voz alta de um conteúdo previamente elaborado.

Essa situação - o discurso intelectual escrito mais valorizado perante a fala improvisada, relegada ao status de recurso indesejável - chega à prática educacional da mesma forma: o professor é um "ator" que traz o conteúdo pronto em uma tradição que tem a rigidez como princípio. O improviso não encontra espaço em sala de aula, visto como algo negativo, como sinal de inexperiência do professor.

\section{Uma visão positiva sobre o improviso em sala de aula}

Embora a visão sobre o improviso esteja geralmente condicionada por esses pressupostos negativos, é possível encontrar várias propostas educacionais e estudos sobre ensino e aprendizagem que o considerem sob vieses inclusivos ou até mesmo como uma necessidade por parte dos professores.

Nunes (2004) defende, por exemplo, que a prática da docência fundamenta-se no conceito do "saber da experiência", que seria formado por três eixos: o improviso na sala de aula, a rotina do professor como experiência adquirida e a experiência ganha, que se converte em segurança. A improvisação, segundo a autora, "pode ser considerada como um saber resultante da experiência adquirida" (NUNES, 2004, p.112). Nas pesquisas elaboradas em sua tese, Nunes expõe a improvisação como foco de divergências nas opiniões dos professores entrevistados: alguns carregavam a noção dele como algo negativo, advindo da falta de 
planejamento ou "descompromisso", enquanto outros o exaltavam como expressão de criatividade e inovação na sala de aula.

É notada, entretanto, a recorrência do improviso como uma prática constante em sala de aula, que poderia ter relação com o tempo de experiência do professor. Citando Perrenoud, Nunes reconhece o caráter inevitável do improviso dentro da sala de aula: "a atividade de ensinar tem a incerteza como algo permanente, em que o professor, muitas vezes, deverá reagir com precisão diante de situações imprevistas resolvendo-as sem muitos prejuízos" (PERRENOUD, 2001 apud NUNES, 2004, p. 118). Quanto a isso, a autora complementa: “O reconhecimento da existência de um caráter de improvisação na ação pedagógica da sala de aula não sugere que o professor dispense a elaboração de um projeto ou de uma preparação prévia” (NUNES, 2004, p. 119). Portanto o improviso em sala aparece, na visão da autora, como um elemento enriquecedor, que contribui para a aprendizagem em conjunto com os conteúdos pré-estabelecidos.

Essa constatação encontra-se também no discurso de Sawyer (2004, p. 16), que defende o conceito de "improvisação disciplinada": um processo dinâmico entre planejar e improvisar. Ou seja, reconhece-se a necessidade e existência do currículo e da ementa, mas a flexibilidade para improvisar diante de exercícios, discussões, reações dos alunos é mantida como essencial para a prática da docência. Deste modo, para o autor, os professores mais efetivos são os que conseguem transitar entre o que foi planejado previamente e o improvisado, que conseguem perceber e responder às necessidades únicas da classe, mesmo que para isso seja necessário improvisar falas, materiais ou exercícios (SAWYER, 2004, p. $17)$.

Cunha et. al. (2015), não articulando especificamente sobre o improviso em sala de aula (mas também aplicável a este contexto), abordam como o ato de improvisar surge naturalmente ao seres humanos, como uma contraparte ao que é organizado. Nesse quesito, os autores apontam a existência de quatro manifestações do improviso: episódico, subversivo, resistivo e semiestruturado. O improviso episódico seria aquele informal, mas desejável surge como solução aos problemas e imprevistos (os autores exemplificam com a missão Apollo 13, na qual um desastre foi evitado graças à capacidade de improviso dos astronautas); o subversivo, também informal e desejável, seria como uma fonte de inovação e criatividade; já o resistivo seria considerado informal e indesejável, já que aparece como oposição à ordem; por fim, o improviso semiestruturado surge como formal e desejável, dentro de uma 
organização permissiva, ou seja, ocorre dentro de um espaço pré-estabelecido. (CUNHA et. al., 2015, p.5-9)

Deixar o improviso se manifestar estruturalmente dentro da sala de aula iria ao encontro do que Almeida sugere como "pedagogia da escolha” (ALMEIDA, 2015). Segundo o autor, o ensino deveria ocorrer em um ambiente no qual não existem valores universais, apenas regras que se aplicam a casos precisos:

No âmbito da pedagogia da escolha, e para que escolha possa haver, enfatiza-se a poética da experimentação contra a política da imposição que circula nas escolas, na mídia, nos templos religiosos e nos demais espaços que se incumbem da hierarquização e distribuição dos valores simbólicos do conhecimento, da informação, da arte, da fé... (ALMEIDA, 2015, p.185)

O improviso, tanto por parte do professor na hora de ensinar quanto como uma ferramenta acessível para os alunos, teria espaço na sala de aula justamente por favorecer a escolha em contraparte às práticas impositivas do ensino tradicional. Esse processo é descrito por Almeida como "desaprendizagem": quando o aluno, despido de suas crenças e pressupostos, está pronto para afirmar o mundo e reconhecer o real em sua totalidade, considerando seus aspectos dolorosos e indigestos (ALMEIDA, 2013, p. 1013).

\section{Ensino no design: alguns depoimentos}

Para a apresentação deste artigo no primeiro Seminário sobre Ensino em Design da UFPR (agosto de 2016), foram entrevistados três professores de cursos de design (dois da UFPR e uma professora da UTFPR). Nas entrevistas, apenas um pergunta foi feita: o professor(a) já precisou improvisar em algum momento na sala de aula?

Os três professores deram respostas positivas, que podem ser conferidas abaixo na transcrição íntegra, apenas omitindo a identidade de cada professor. O primeiro é de uma professora do curso de design gráfico da UFPR:

\footnotetext{
"Bom, como qualquer atividade humana, que se estabelecem relações, por mais que a gente tente controlar todos os pontos e as dinâmicas, sempre tem algum ponto que escapa. Então, a sala de aula não é diferente. Quando a gente prepara todos os itens...sim, isso acontece...o improviso é algo recorrente. A questão é que a gente tem que estar preparada para ele, né? Eu digo as vezes que a gente tem que considerar o plano $\mathrm{A}$, o plano $\mathrm{B}$, o plano $\mathrm{C}$, o D, o F... E eu acho que nessas situações, tentar trabalhar com os alunos, talvez até revelar um pouco isso, às
} 
vezes a gente tenta falsear um pouco...não falsear..., mas assim, tenta dissimular que algo não está dando errado, né? Ou que algo previsto não é acontecendo... às vezes é melhor compartilhar, buscar soluções junto com os alunos, ou com algum par, né? Acho que essas seriam situações típicas de improviso em sala de aula. Mas que elas ocorrem, ocorrem, e a certeza que elas vão ocorrer".

O segundo depoimento é de um professor do curso de design de produto da mesma instituição:

“Acho que em nenhum momento eu não precisei improvisar. Todas as aulas, por mais que a gente tenha um fio condutor, uma linha do que eu vou abordar naquele dia, naquela aula, elas são sempre diferentes. Em todo momento você está tendo que improvisar porque as perguntas mudam, as pessoas mudam, as gerações mudam. Isso ficou muito claro, por exemplo, em um ano que eu dei a mesma disciplina para duas turmas diferentes. Eu não conseguia dar exatamente a mesma aula pra essas duas turmas, eles tinham respostas diferentes. Eu não acredito que a gente não tenha que, em algum momento, improvisar. E não que isso seja ruim: faz parte da própria dinâmica do ensino."

A terceira entrevistada é uma professora aposentada do curso de design da UTFPR:

"Eu comecei a dar aula muito nova, no técnico, quando eu tinha 19 anos. Eu dei aula à noite, quando eu tive alunos mais velhos do que eu. Pela própria imaturidade, eu já tive momento em que eu cheguei na sala de aula e tive que improvisar mesmo, inventar alguma coisa. Como eu trabalhava com desenho, eu acho que fica mais fácil. O improviso acaba sendo produtivo, muitas vezes: o que você pensa que é improviso na verdade acaba se tornando uma metodologia. Com o tempo eu fui entendendo isso. Se pedir pro aluno expressar alguma coisa pelo desenho, no momento parece que você está preenchendo o tempo que sobrou. Você planejava uma aula pra 50 minutos e quando via, em 30 ela já acabou. 'E agora, o que que vou fazer?' E aí comecei a entender que esse improviso faz parte e acaba constituindo uma metodologia de ensino."

Os depoimentos sugeriram que, conforme prevê a literatura pesquisada, a prática é inevitável e, em vez de indesejável, é tratada como uma ferramenta necessária para o bom andamento da aula. Os três professores mencionaram o improviso da forma como Cunha (2015) descreve as situações episódicas e subversivas: apesar de não ser esperado, sua ocorrência é desejável. 
Um dos professores menciona que ele nunca precisou "não improvisar" na sala de aula: segundo ele, as pessoas mudam e as perguntas mudam. $\mathrm{O}$ ensino no design é dinâmico e requer que o professor esteja sempre atento ao que os alunos demandam.

\title{
Considerações finais
}

Durante as articulações sobre o ensino tradicional, alguns pontos de resistência ao improviso foram identificados, seja com o pressuposto de que a prática do improviso pode ser associada ao que é negativo (como falta de experiência), seja com a valorização da aula roteirizada e rígida. Em contrapartida, o improviso foi apresentado como uma ferramenta que pode ser incorporada na estratégia do ensino, que tem espaço como parte da rotina disciplinada dos docentes e que serve como alternativa pedagógica que suscite escolha e flexibilidade em sala de aula. Além disso, mesmo que brevemente, destacou-se a presença constante do improviso no ensino superior de design.

Como possíveis desdobramentos a esse artigo, propomos a investigação sobre se - e como - a sala de aula pode ser ambiente potencial para o improviso semiestruturado, conceito que foi definido por Cunha et. al. (2015), e também a discussão se é possível que o improviso atue como ferramenta em favor tanto do ensino - na flexibilidade do professor em sala de aula - quanto da aprendizagem - junto com exercícios e a colaboração dos alunos. Como último desdobramento, propomos a investigação dos motivos pelos quais o improviso é constante no ensino de design, em específico - e como isso poderia ser aproveitado e repassado aos novos docentes da área.

\section{The presence of improvisation in the teaching practice}

\author{
Abstract \\ This paper presents a discussion about improvisation occurrences in the teaching practice, \\ especially in design college courses. First of all, the concept of traditional teaching is \\ presented, as well as its position regarding the impromptu practices that may occur in the \\ classroom environment. Then, contemporary views about improvisation are described in a \\ counter-argument, concluding with testimonials from design professors about the experience
}


of improvising while teaching. At last, as final considerations, other developments are presented as results of this discussion.

Keywords: Improvisation, Teaching, Design.

\section{Referências}

ALMEIDA, R. O mundo, os homens e suas obras: filosofia trágica e pedagogia da escolha. Tese (Livre-docência em Filosofia da Educação). São Paulo: Universidade de São Paulo, 2015 .

ALMEIDA, R. Aprendizagem de desaprender: Machado de Assis e a pedagogia da escolha. Educação e Pesquisa (PPGE-USP), v. 39, n. 4, out./dez. 2013, p. 1001-1016.

COLLI, G. O nascimento da filosofia. Campinas: Editora da Unicamp, 1996.

CUNHA M. P.; NEVES, P.; CLEGG, S. R.; REGO, A. Tales of the unexpected: discussing improvisational learning. SAGE Management Learning, v. 46, n.5, p. 1-19, nov./2015.

MICHAELIS. Definição de improviso. Editora Melhoramentos, 2016. Disponível em: <http://goo.gl/2tiZh9>.

NUNES, C. M. F. O saber da experiência de professores de séries iniciais: condições de produção e formas de manifestação. Tese (Doutorado em Educação Brasileira). Rio de Janeiro: Pontifícia Universidade Católica do Rio de Janeiro, 2004.

RODRIGUES, L. P.; MOURA, L. S.; TESTA, E. O tradicional e o moderno quanto à didática no ensino superior. Revista científica do ITPAC, Araguaína, v.4, n.3, pub. 5, jul./2011.

SAWYER, R. K. Creative teaching: collaborative discussion as disciplined improvisation. SAGE Educational Researcher, v. 33, n.2, p.12-20, mar./2004. 